\title{
施肥对稻田生态系统气体调节功能及其价值的影响
}

\author{
肖 玉 $^{1,2}$ 谢高地 $^{1}$ 鲁春霞 $^{1}$ 丁贤忠 $^{1}$ 吕 耀 $^{1}$ \\ （1 中国科学院地理科学与资源研究所, 北京 100101）（2 中国科学院研究生院, 北京 100039）
}

\begin{abstract}
摘 要 该文以 2002 年在上海市奉贤县五四农场进行的稻田生态系统田间实验为基础, 对尿素施用对稻田生态系 统气体调节功能(释放 $\mathrm{O}_{2}$ 和温室气体调节)的影响进行研究。研究结果表明: 1) 在水稻 (Oryza sativa) 生长期间, 施 加尿素能显著增加稻田日 $\mathrm{O}_{2}$ 释放量及其价值量; 2 )在水稻生长期间, 施加尿素稻田综合 $\mathrm{CO}_{2}$ 的通量及其价值并不 比未施肥稻田存在显著优势, 尿素施用能明显增强稻田 $\mathrm{N}_{2} \mathrm{O}$ 排放通量, 降低稻田 $\mathrm{CH}_{4}$ 排放通量。尿素施用对温室 气体调节具有正效应, 促进稻田对温室气体吸收。
\end{abstract}

关键词 气体调节 稻田生态系统 生态系统服务功能 价值评估 施肥

\section{THE IMPACT OF UREA AMENDMENTS ON ATMOSPHERIC GAS REGULATION SERVICES IN RICE PADDY ECOSYSTEMS AND THEIR VALUATION}

\author{
XIAO Yu ${ }^{1,2}$ XIE Gao-Di ${ }^{1}$ LU Chun-Xia ${ }^{1}$ DING Xian-Zhong ${ }^{1}$ and LÜ Yao ${ }^{1}$ \\ (1 Institute of Geographic Sciences and Natural Resources Research, Chinese Academy of Sciences, Beijing 100101, China) \\ (2 Graduate School of Chinese Academy of Sciences, Beijing 100039, China)
}

\begin{abstract}
The services provided by croplands have been underestimated. Besides providing food and fiber, croplands provide many other functions and services, such as nutrient transformation, pollination, biological control, beautiful scenery, recreation, and so on. In this study, gas regulation services provided by fertilized and unfertilized rice (Oryza sativa) paddy ecosystems and their values were investigated based on field experiments conducted on the Wusi Farm in Fengxian County, Shanghai in 2002. Paddy fields regulated two types of gases: $\mathrm{O}_{2}$ emissions and greenhouse gases ( GHGs), including $\mathrm{CO}_{2}$ uptake and $\mathrm{CH}_{4}$ and $\mathrm{N}_{2} \mathrm{O}$ emissions .

At elongation stage, booting stage, panicle initiation stage and maturation stage, the biomass of fertilized and unfertilized paddy fields were determined and $\mathrm{O}_{2}$ emissions calculated using the photosynthesis formula based on plant biomass. The maximum $\mathrm{O}_{2}$ emissions from fertilized and unfertilized paddy fields were 770.15 and $506.62 \mathrm{~kg} \bullet \mathrm{hm}^{-2} \bullet \mathrm{d}^{-1}$, respectively. Compared to the price of industrial $\mathrm{O}_{2}$ and the cost of afforestation in China, their values were calculated as 190.72 and 289.93 yuan $\bullet \mathrm{hm}^{-2} \cdot \mathrm{d}^{-1}$.

On August 15, 18, 21 and 25, and September 2, 8, 14 and 22, the gases from paddy fields were sampled and their fluxes determined. The results showed that the fluxes of $\mathrm{CH}_{4}$ from fertilized and unfertilized paddy fields ranged from $4.86 \mathrm{mg} \cdot \mathrm{m}^{-2} \cdot \mathrm{h}^{-1}$ to $14.96 \mathrm{mg} \cdot \mathrm{m}^{-2} \cdot \mathrm{h}^{-1}$ and from $3.34 \mathrm{mg} \cdot \mathrm{m}^{-2} \cdot \mathrm{h}^{-1}$ to $50.67 \mathrm{mg} \bullet$ $\mathrm{m}^{-2} \cdot \mathrm{h}^{-1}$, respectively. For $\mathrm{N}_{2} \mathrm{O}$, they ranged from $0.0086 \mathrm{mg} \cdot \mathrm{m}^{-2} \cdot \mathrm{h}^{-1}$ to $0.0566 \mathrm{mg} \cdot \mathrm{m}^{-2} \cdot \mathrm{h}^{-1}$ and from $0.0006 \mathrm{mg} \cdot \mathrm{m}^{-2} \cdot \mathrm{h}^{-1}$ to $0.0149 \mathrm{mg} \cdot \mathrm{m}^{-2} \cdot \mathrm{h}^{-1}$, and for $\mathrm{CO}_{2}$ from $347.63 \mathrm{mg} \cdot \mathrm{m}^{-2} \cdot \mathrm{h}^{-1}$ to $730.20 \mathrm{mg}^{\bullet} \mathrm{m}^{-2}$ $\cdot \mathrm{h}^{-1}$ and from $205.06 \mathrm{mg} \cdot \mathrm{m}^{-2} \cdot \mathrm{h}^{-1}$ to $679.51 \mathrm{mg} \cdot \mathrm{m}^{-2} \cdot \mathrm{h}^{-1}$, in fertilized and unfertilized paddy fields, respectively. Using a $\mathrm{CO}_{2}$ equivalent, the integrated GHGs fluxes were computed as $-1.42-39.71 \mathrm{~kg}^{\bullet} \mathrm{hm}^{-2}$ • $\mathrm{d}^{-1} \mathrm{CO}_{2}-\mathrm{C}$ ( fertilized) and $-50.56-25.60 \mathrm{~kg} \bullet \mathrm{hm}^{-2} \bullet \mathrm{d}^{-1} \mathrm{CO}_{2}-\mathrm{C}$ ( unfertilized). Based on the average cost of the Sweden carbon tax and afforestation in China, the economic value of GHGs regulation was calculated. The results indicated that the valuation of $\mathrm{CO}_{2}$ absorption by fertilized paddy fields was not much more than that by unfertilized ones. Second, urea amendment aggravated the negative values of $\mathrm{N}_{2} \mathrm{O}$ emissions from paddy fields. Third, the negative values of $\mathrm{CH}_{4}$ emission from paddy fields were mitigated by urea amendment. And fourth, the valuation of GHGs regulation by fertilized fields was promoted by urea amendments. In this study, we were trying to provide a fair method to evaluate the values of croplands to support an effective way to recognize the benefits derived from croplands, especially by paddy fields, and to promote the sustainability of crop-
\end{abstract}


land ecosystems.

Key words Gas regulation, Paddy fields, Ecosystem services, Value assessment, Urea amendment

在农田生态系统为人类提供的众多服务与功能 中 (Paoletti et al., 1992; Björklund et al., 1999), 气 体调节就是其中之一。气体调节功能包括生态系统 调节大气和调节气候的功能, 主要指生态系统调节 大气化学成分以及调节全球气温、降水和其它全球 或区域范围内的气候过程等(Costanza et al., 1997)。 由于有人类活动的参与, 具有高光合作用效率的农 田生态系统每年固定大量的 $\mathrm{CO}_{2}$ 并释放大量的 $\mathrm{O}_{2}$ 。 全球植被年固定的 $5.3 \times 10^{8} \mathrm{Mg} \mathrm{C}$ 碳中, 作物吸收碳 量占 $47 \%$, 草原吸收 $10 \%$, 森林固碳量占 $43 \%$ (王修 兰, 1996)。当然作物在生长过程中还通过土壤和 作物呼吸作用向大气排放大量 $\mathrm{CO}_{2}$, 此外农田特别 是稻田生态系统还是 $\mathrm{CH}_{4}$ 和 $\mathrm{N}_{2} \mathrm{O}$ 等温室气体的排 放源。Björklund 等 (1999)研究表明, 由于生产效率 的提高, 从 20 世纪 40 年代到 90 年代瑞典农业景观 排放温室气体量从 $3210 \mathrm{~kg} \cdot \mathrm{hm}^{-2} \mathrm{CO}_{2}$ 减少到 2500 $\mathrm{kg} \cdot \mathrm{hm}^{-2} \mathrm{CO}_{2}$ 。 Robertson 等(2000)研究了美国农业 系统 $\mathrm{CO}_{2} 、 \mathrm{~N}_{2} \mathrm{O}$ 和 $\mathrm{CH}_{4}$ 气体排放, 并认为考虑到农业 投入生产过程中排放的温室气体、作物收获导致的 碳损失以及土壤和作物本身排放的温室气体, 每年 耕作的农业系统没有净吸收大气中温室气体。邹建 文等(2003)研究江苏省南京市稻田发现, 由植物固 定 $\mathrm{CO}_{2}$ 吸收的碳量减去土壤释放 $\mathrm{CO}_{2}$ 和 $\mathrm{CH}_{4}$ 产生的 碳量后得到的结果显示, 稻田生态系统表现为对大 气中碳的净吸收。生态系统服务功能的价值评估虽 然存在很多争议, 但仍然有很多学者做着有益的尝 试(Costanza et al ., 1997; Daily，1997), 关于农田生 态系统气体调节功能的价值评价也是如此(欧阳志 云等, 1999; 谢高地等, 2003)。本研究根据稻田生 态系统田间实验, 对在水稻 (Oryza sativa) 生长期间 施肥和未施肥稻田气体调节功能(包括固定 $\mathrm{CO}_{2}$, 释 放 $\mathrm{O}_{2}$, 排放 $\mathrm{CO}_{2} 、 \mathrm{CH}_{4}$ 和 $\mathrm{N}_{2} \mathrm{O}$ 等功能) 变化过程及其 影响因素进行了研究。

\section{1 实验和方法}

\section{1 研究区概况}

上海五四农场位于上海市南郊奉贤县境内, 具 有明显的北亚热带季风气候特征。土壤以中性壤土 为主, 少数为重质壤土, $0 \sim 20 \mathrm{~cm}$ 耕作层含盐量为 $0.8 \%$, 有机质为 $12 \sim 14 \mathrm{~g} \bullet \mathrm{kg}^{-1}$, 水解氮 $(\mathrm{N})$ 为 60.5 $\mathrm{mg} \bullet \mathrm{kg}^{-1}$, 速效磷 $(P)$ 为 $23.1 \mathrm{mg} \bullet \mathrm{kg}^{-1}$, 速效钾 $(K)$ 为
$230 \mathrm{mg} \bullet \mathrm{kg}^{-1}, \mathrm{pH}$ 值为 $7.9 \sim 8.0$, 地下矿化度为年均 $5.1 \mathrm{~g} \cdot \mathrm{L}^{-1}$ 。供试水稻品种为 ' 9734 ', 直播, 播量为 $127.5 \mathrm{~kg} \cdot \mathrm{hm}^{-2}$ 。除施氮水平之外, 小区其它投入及 管理措施与大田常规管理相同。实验设计分为未施 氮和施氮( 尿素 $375 \mathrm{~kg} \mathrm{~N} \cdot \mathrm{hm}^{-2}$, 在分睬期和抽穗期 分 4 次施用)两个处理, 每个处理设 3 次重复, 小区 随机分布。

\section{2 主要研究方法}

1.2.1 稻田温室气体排放实验监测及其排放量和 价值计算

本试验测定稻田主要生育期温室气体 $\left(\mathrm{CO}_{2}\right.$ 、 $\mathrm{CH}_{4}$ 和 $\mathrm{N}_{2} \mathrm{O}$ ) 的排放通量, 采用静态箱法于 2002 年 8 月 $15 、 18 、 21$ 和 25 日; 9 月 2、8、14 和 22 日上午 9:00 $\sim 11: 00$ 人工采集气体样品, 每次采样取 3 次重复。 $\mathrm{CH}_{4}$ 和 $\mathrm{N}_{2} \mathrm{O}$ 利用惠普 5890 II 型气相色谱仪分析, $\mathrm{CO}_{2}$ 浓度利用 LI-COR6252 型 $\mathrm{CO}_{2}$ 红外分析仪测定。由 于在一定的时间段内, 稻田温室气体排放浓度的变 化成线性增长 (减少), 所以可以根据箱内气体浓度 随时间变化来计算稻田气体排放通量:

$$
F=\frac{d m}{A \cdot d t}=\frac{d c \cdot V \rho}{A \cdot d t}=\frac{M P h}{\mathrm{R} T} \cdot \frac{d c}{d t}
$$

式中, $F$ 为气体排放通量 $\left(\mathrm{mg} \cdot \mathrm{m}^{-2} \cdot \mathrm{h}^{-1}\right), \rho$ 为气体 密度, $\mathrm{R}$ 为气体常数, $d m$ 和 $d c$ 分别为 $d t$ 时间内采集 箱内气体质量和浓度的变化, $h 、 A 、 V$ 分别为气箱高 度 $(\mathrm{m})$ 、底面积 $\left(\mathrm{m}^{2}\right)$ 和体积 $\left(\mathrm{m}^{3}\right), M$ 为气体分子量, $T$ 为气箱内温度, $P$ 为气箱内气压。

参照 IPCC( 1992) 推荐的稻田甲烷排放量估算 的方法, 估算不同生育期稻田温室气体排放量。稻 田温室气体主要包括 $\mathrm{CH}_{4} 、 \mathrm{~N}_{2} \mathrm{O}$ 和 $\mathrm{CO}_{2}$ 等, 运用增温 潜势 (Global warming potentials, GWP; 以 $\mathrm{CO}_{2}$ 的 $G W P$ 为 1) 将 $\mathrm{CH}_{4}$ 和 $\mathrm{N}_{2} \mathrm{O}$ 换算为 $\mathrm{CO}_{2}$, 计算其气体调节的 价值。对于 100 年时间尺度的气候变化, $\mathrm{CH}_{4}$ 和 $\mathrm{N}_{2} \mathrm{O}$ 的 GWP 分别为 24.5 和 320 (Björklund et al., 1999)。 稻田生态系统气体调节价值运用造林成本法 (0.2609 yuan $\cdot \mathrm{kg}^{-1}$; 欧阳志云等, 1999) 和碳税法 (1.245 yuan $\mathrm{kg}^{-1}$; 国家环境保护局，1997）计算。 稻田生态系统排放温室气体造成了全球气温的增 高, 其价值为负。

1.2.2 稻田干物质生产量的测定和释放 $\mathrm{O}_{2}$ 物理量 和价值量的估算

利用样方收获法在水稻关键生育期测定水稻地 
上和地下干物质生产量, 然后通过光合作用方程计 算稻田生态系统释放的 $\mathrm{O}_{2}$ (欧阳志云等, 1999)。

$6 \mathrm{CO}_{2}+6 \mathrm{H}_{2} \mathrm{O} \rightarrow \mathrm{C}_{6} \mathrm{H}_{12} \mathrm{O}_{6}+6 \mathrm{O}_{2} \rightarrow \mathrm{C}_{6} \mathrm{H}_{10} \mathrm{O}_{5}$

据上式, 植物体每积累 $1 \mathrm{~g}$ 干物质, 释放 $1.19 \mathrm{~g}$ $\mathrm{O}_{2}$ 。根据各生育期水稻干物质生产量可反推出稻田 生态系统在这期间的光合作用过程中释放 $\mathrm{O}_{2}$ 的量, 将其在生育期内平均, 可得到该生育期内的日变化 量。在计算稻田生态系统释放 $\mathrm{O}_{2}$ 的价值时, 采用造 林成本法 (0.352 9 yuan $\mathrm{kg}^{-1}$; 欧阳志云等, 1999)和 工业制氧法( 0.4 yuan・ $\mathrm{kg}^{-1}$; 欧阳志云等, 1999)计 算。

\section{$\mathbf{1 . 2 . 3}$ 统计分析}

本研究运用 SPSS11.5 软件对研究结果进行统 计分析, 并对不同处理数据之间的显著性差异进行 了检验。

\section{2 结果与分析}

\section{1 稻田生态系统生物量}

水稻总生物量从生长季初期开始增长, 在播种 后 75、86 和 $98 \mathrm{~d}$ (拔节期和抽穗期)迅速增加, 在灌 浆期达到最大值。这主要是由于 7 月中旬至 8 月下 旬是该地区高温较为集中的时段, 充足的热量和光 照促进了植物的光合作用 (表 1)。其后由于光合作 用强度的不断减弱, 总生物量缓慢下降。这与 Singh 等(1999)在印度观测到的移栽稻生长发育情况一 致。周卫军等(2003) 也得出分藮至齐穗期是水稻生 物生产量增加最为迅速的时期。施氮肥对水稻生物
量生产有明显影响: 由于氮素代谢直接影响植物生 物量的形成, 在整个水稻生育期内, 施肥稻田水稻总 生物量均显著高于未施肥稻田(表 1)。

\section{2 稻田生态系统 $\mathrm{O}_{2}$ 释放量及其价值}

由光合作用方程可知, 稻田生态系统 $\mathrm{O}_{2}$ 释放量 与稻田干物质生产量成线性关系, 因此 $\mathrm{O}_{2}$ 日释放量 季节变化趋势与稻田生态系统干物质日增加量季节 变化趋势一致。在未施肥和施肥的稻田生态系统 中, $\mathrm{O}_{2}$ 日释放量在拔节期以前因为光合作用较弱, 所以增长缓慢; 而水稻拔节期和齐穗期正值 7 月下 旬至 8 月下旬持续的高温天气, 水稻光合作用强度 大, $\mathrm{O}_{2}$ 日释放量迅速增加, 在齐穗期达到最大值, 分 别为 506.62 (未施肥) 和 $770.15 \mathrm{~kg} \cdot \mathrm{hm}^{-2} \cdot \mathrm{d}^{-1}$ (施 肥); 之后随着水稻逐渐成熟, 光合作用强度减弱, $\mathrm{O}_{2}$ 日释放量将下降 (表 2)。是否施用氮肥对水稻 $\mathrm{O}_{2}$ 日释放季节变化也有明显影响: 在播种后 $0 \sim 75 \mathrm{~d}$ 和播种后 $86 \sim 98 \mathrm{~d}$ 施肥和不施肥处理的 $\mathrm{O}_{2}$ 日释放 量存在显著差异 $(p<0.05)$; 而播种后 $75 \sim 86 \mathrm{~d}$ 施 肥和不施肥处理的 $\mathrm{O}_{2}$ 日释放量的差异并不显著(表 2)。在水稻生育期内稻田日释放 $\mathrm{O}_{2}$ 的价值量与物 理量有着相同的趋势: 在物理量达到极值的齐穗期, 价值量也达到最大值, 分别为 190.72 和 289.93 yuan $\cdot \mathrm{hm}^{-2} \cdot \mathrm{d}^{-1}$ 。施用氮肥能提高稻田植物光合作用的 强度, 其 $\mathrm{O}_{2}$ 日释放的价值量最大值高于未施肥稻 田。

2.3 稻田生态系统温室气体调节及其价值

2.3.1 稻田生态系统温室气体调节

表 1 不同生育期水稻生物生产量 (平均值 \pm 标准差)

Table 1 The biomass of paddy during the different stages $($ Mean $\pm S D)$

\begin{tabular}{ccccc}
\hline $\begin{array}{c}\text { 处理 } \\
\text { Treatment }\end{array}$ & $\begin{array}{c}\text { 播种后 } 75 \mathrm{~d} \\
75 \text { days after seeding }\end{array}$ & $\begin{array}{c}\text { 播种后 } 86 \mathrm{~d} \\
86 \text { days after seeding }\end{array}$ & $\begin{array}{c}\text { 播种后 } 98 \mathrm{~d} \\
98 \text { days after seeding }\end{array}$ & $\begin{array}{c}\text { 播种后 } 120 \mathrm{~d} \\
120 \mathrm{days} \text { after seeding }\end{array}$ \\
\hline 未施肥 Unfertilized & $5817 \pm 355^{* *}$ & $10500 \pm 1067^{*}$ & $16170 \pm 1313^{*}$ & $13881 \pm 1193^{* *}$ \\
施肥 Fertilized & $10038 \pm 477^{* *}$ & $17157 \pm 2590^{*}$ & $26460 \pm 3377^{*}$ & $23982 \pm 1530^{* *}$ \\
\hline
\end{tabular}

$*: p<0.05 * *: p<0.01$

表 2 稻田生态系统释放 $\mathbf{O}_{2}$ 的物理量和价值量变化 (平均值 \pm 标准差)

Table 2 The variation of $\mathrm{O}_{2}$ emissions from paddy fields and their values $($ Mean $\pm S D$ )

\begin{tabular}{cccc}
\hline $\begin{array}{c}\text { 播种后天数 }(\mathrm{d}) \\
\text { Days after seeding }\end{array}$ & $\begin{array}{c}\text { 处理 } \\
\text { Treatment }\end{array}$ & $\begin{array}{c}\text { 日释放 } \mathrm{O}_{2} \text { 量 } \\
\mathrm{O}_{2} \text { emission per day }\left(\mathrm{kg} \bullet \mathrm{hm}^{-2} \bullet \mathrm{d}^{-1}\right)\end{array}$ & $\begin{array}{c}\text { 经济价值 } \\
\text { Economic value }\left(\mathrm{yuan} \bullet \mathrm{hm}^{-2} \bullet \mathrm{d}^{-1}\right)\end{array}$ \\
\hline $0 \sim 75$ & 不施肥 Unfertilized & $92.30 \pm 5.63^{*}$ & $34.75 \pm 2.12^{*}$ \\
& 施肥 Fertilized & $159.27 \pm 7.57^{*}$ & $59.96 \pm 2.85^{*}$ \\
$75 \sim 86$ & 不施肥 Unfertilized & $506.62 \pm 77.02$ & $190.72 \pm 29.00$ \\
& 施肥 Fertilized & $770.15 \pm 127.14$ & $289.93 \pm 47.86$ \\
& 不施肥 Unfertilized & $306.70 \pm 13.30^{*}$ & $115.46 \pm 5.01^{*}$ \\
& 施肥 Fertilized & $503.21 \pm 33.95^{*}$ & $189.44 \pm 12.78^{*}$ \\
\hline
\end{tabular}




\subsubsection{1 稻田排放 $\mathrm{CH}_{4}$}

本研究中稻田采用间歇性灌溉管理方式, 分别 于水稻播种后 $38 \mathrm{~d} 、 42 \sim 48 \mathrm{~d}$ 和 $50 \sim 56 \mathrm{~d}$ 烤田, 该措 施被证明能显著减少稻田 $\mathrm{CH}_{4}$ 排放 ( Yang \& Chang, 1999)。本研究结果显示, 稻田 $\mathrm{CH}_{4}$ 排放通量从播种 后 70 90 d( 拔节后期至抽穗期前) 有轻微波动, 至 抽穗扬花期达到峰值 (图 1a), 这与 Singh 等(1999)的 研究结果相同。这主要是由于一方面水稻植株在该 段时间生长旺盛, 根脱落物和分泌物为产 $\mathrm{CH}_{4}$ 细菌 提供了充足的前体; 另一方面在生殖生长期水稻植 株根系周围形成的强还原环境促进了 $\mathrm{CH}_{4}$ 的产生 (Adhya et al., 1994); 同时 8 月下旬至 9 月初持续的 高温天气增加土壤温度, 促进了土壤有机质降解, 刺 激了产 $\mathrm{CH}_{4}$ 细菌的活性, $\mathrm{CH}_{4}$ 排放通量不断增加 (Yang \& Chang, 1999)。此后, 由于气温逐渐降低, 同时水稻植株根系表皮逐渐老化导致 $\mathrm{CH}_{4}$ 传输能 力减弱, 稻田 $\mathrm{CH}_{4}$ 的排放通量逐渐降低 (Nouchi et al., 1994)。

施肥对稻田 $\mathrm{CH}_{4}$ 排放通量的影响非常复杂, 研 究结果也存在很大分歧 (Lindau et al., 1991;
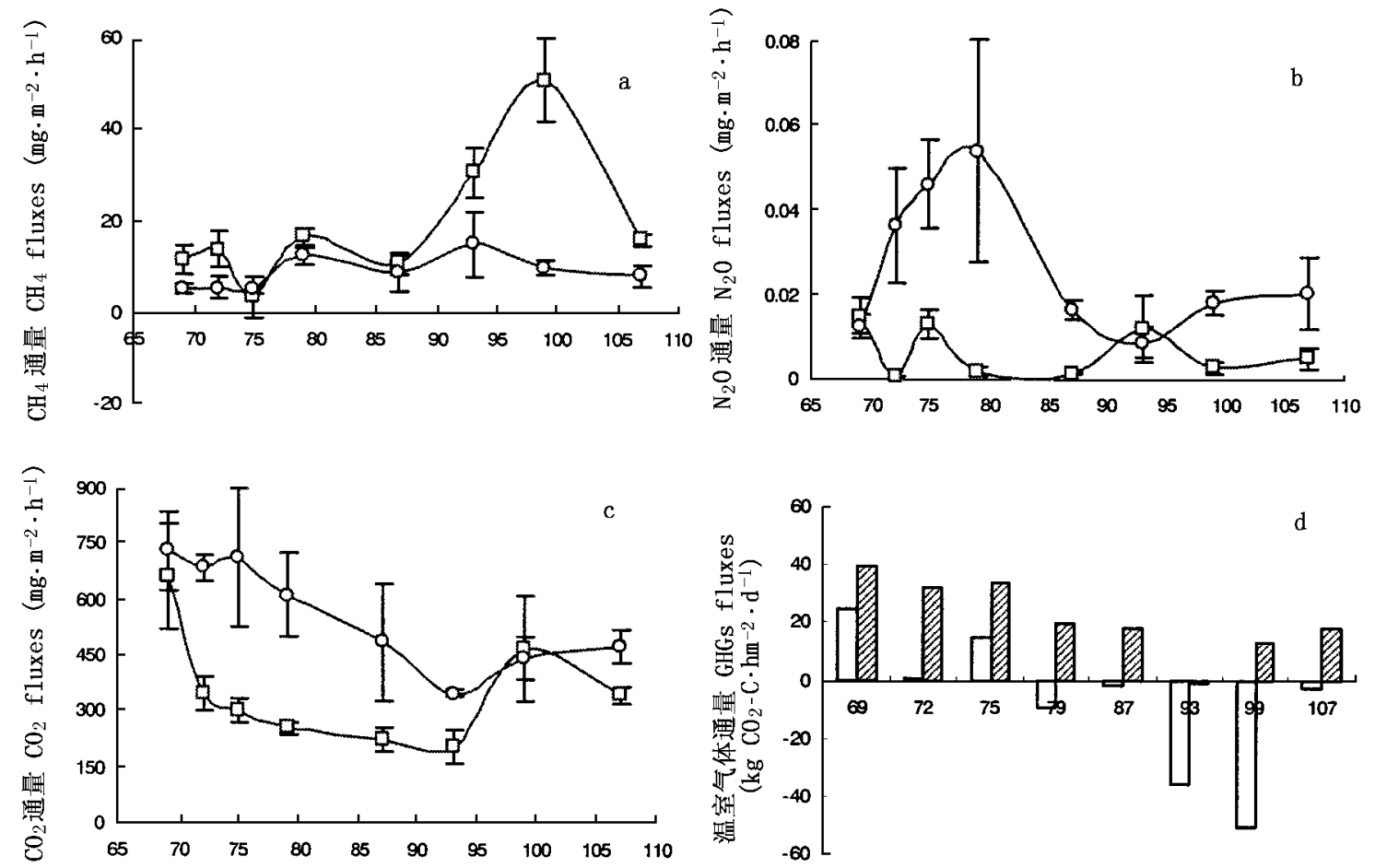

播种后天数 Days after seeding (d)
Whalenm et al., 1991; 上官行健和王明星, 1993）。 本研究结果显示, 在 8 次观测结果中, 有 5 次施肥和 不施肥稻田 $\mathrm{CH}_{4}$ 排放通量之间存在显著差异, 且不 施肥稻田高于施肥稻田, 因此施用尿素可能抑制了 稻田 $\mathrm{CH}_{4}$ 的排放 (表 3)。在整个生育期内, 施肥和 未施肥稻田 $\mathrm{CH}_{4}$ 排放通量波动范围分别为 4.86 14.96 和 $3.34 \sim 50.67 \mathrm{mg} \cdot \mathrm{m}^{-2} \cdot \mathrm{h}^{-1}$ 。施肥不仅缩小 了稻田 $\mathrm{CH}_{4}$ 排放通量变化幅度, 而且使稻田 $\mathrm{CH}_{4}$ 季 节排放量从 476 减少到 $212 \mathrm{~kg} \cdot \mathrm{hm}^{-2}$ 。这主要是因 为大多数产 $\mathrm{CH}_{4}$ 细菌存在的 $\mathrm{pH}$ 值范围为 $6.5 \sim 7.5$ (Mah \& Smith，1981), $\mathrm{pH}$ 值过高或过低将导致 $\mathrm{CH}_{4}$ 产生量的降低( Wang et al., 1993)。本实验小区土 壤 $\mathrm{pH}$ 值为 $7.9 \sim 8.0$, 属碱性土壤, 施用尿素将进一 步增加土壤 $\mathrm{pH}$ 值 (Yang \& Chang, 1998), 导致 $\mathrm{CH}_{4}$ 排放量的减少。

\subsubsection{2 稻田排放 $\mathrm{N}_{2} \mathrm{O}$}

稻田生态系统 $\mathrm{N}_{2} \mathrm{O}$ 排放来自两个过程: 硝化作 用和反硝化作用 (蒋静艳和黄耀, 2001)。本实验的 研究结果显示: 在实验进行的 8 次观测中, 有 6 次结 果表明施尿素稻田 $\mathrm{N}_{2} \mathrm{O}$ 排放通量显著高于不施尿

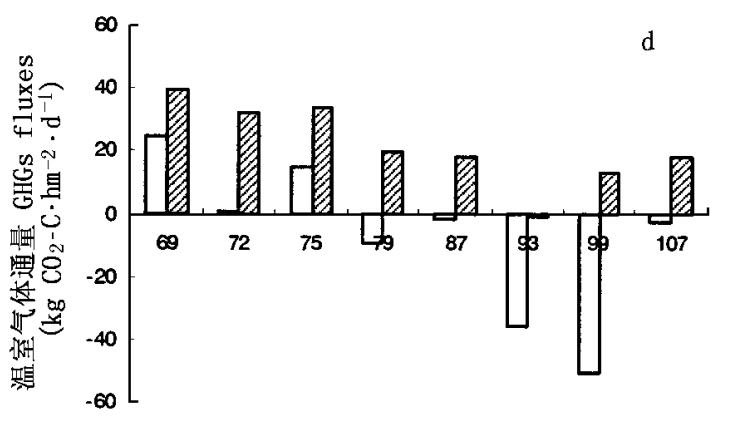


表 3 施肥和不施肥稻田生态系统 $\mathbf{C H}_{4} 、 \mathbf{N}_{2} \mathrm{O}$ 和 $\mathrm{CO}_{2}$ 通量显著性差异检验

Table 3 The test of significant difference of the fluxes of $\mathrm{CH}_{4}, \mathrm{~N}_{2} \mathrm{O}$ and $\mathrm{CO}_{2}$ from fertilized and unfertilized paddy ecosystems

\begin{tabular}{|c|c|c|c|}
\hline $\begin{array}{l}\text { 播种后天数 ( d) } \\
\text { Days after seeding }\end{array}$ & $\begin{array}{c}\mathrm{CH}_{4} \text { 通量的 } F \text { 值 } \\
F \text { value of } \mathrm{CH}_{4} \text { fluxes }\end{array}$ & $\begin{array}{c}\mathrm{N}_{2} \mathrm{O} \text { 通量的 } F \text { 值 } \\
F \text { value of } \mathrm{N}_{2} \mathrm{O} \text { fluxes }\end{array}$ & $\begin{array}{c}\mathrm{CO}_{2} \text { 通量的 } F \text { 值 } \\
F \text { value of } \mathrm{CO}_{2} \text { fluxes }\end{array}$ \\
\hline 69 & $12.15^{*}$ & 0.72 & 0.43 \\
\hline 72 & $10.99^{*}$ & $21.30^{*}$ & $110.28^{* *}$ \\
\hline 75 & 0.31 & $27.40^{* *}$ & $14.02^{*}$ \\
\hline 79 & 6.86 & $11.65^{*}$ & $28.88^{* *}$ \\
\hline 87 & 0.58 & $163.71^{* *}$ & $8.18^{*}$ \\
\hline 93 & $9.29^{*}$ & 0.47 & $25.96^{* *}$ \\
\hline 99 & $58.86^{* *}$ & $78.07^{* *}$ & 0.08 \\
\hline 107 & $29.71^{* *}$ & $9.15^{*}$ & $19.66^{*}$ \\
\hline
\end{tabular}

$*: p<0.05 \quad * *: p<0.01$

素稻田(表 3)。未施肥的稻田生态系统在整个生育 期内保持较低 $\mathrm{N}_{2} \mathrm{O}$ 排放且波动很小，只在播种后 $70 、 74$ 和 $93 \mathrm{~d}$ 排放量有轻微上升。而施氮的稻田在 播种后 $70 \sim 80 \mathrm{~d} \mathrm{~N} \mathrm{~N}_{2} \mathrm{O}$ 排放通量有显著增加, 主要原 因是施加第一次穗肥 (播种后 $63 \mathrm{~d}$ ) 导致土壤中的 $\mathrm{N}$ 素增加, 持续的高温少雨天气使稻田水量下降,土壤 通气和厌气状态同时存在, $\mathrm{N}_{2} \mathrm{O}$ 排放通量较高。播 种后 $74 \mathrm{~d}$ 施加第二次穗肥, 进一步为 $\mathrm{N}_{2} \mathrm{O}$ 的产生补 充了氮源, 加速了 $\mathrm{N}_{2} \mathrm{O}$ 的排放, 导致 $\mathrm{N}_{2} \mathrm{O}$ 排放通量 峰值在播种后 $79 \mathrm{~d}$ 出现。其后两次大量降雨( 播种 后 $81 \mathrm{~d}$ 为 $51 \mathrm{~mm}$ 和 $83 \mathrm{~d}$ 为 $36 \mathrm{~mm}$ ) 使稻田土壤水量 得到补充, $\mathrm{N}_{2} \mathrm{O}$ 排放通量逐渐下降, 至成熟期田间水 量再次下降, $\mathrm{N}_{2} \mathrm{O}$ 排放通量又有所上升( 曹金留等, 1999)。整个生育期施肥和未施肥稻田 $\mathrm{N}_{2} \mathrm{O}$ 排放通 量范围分别为: $0.0086 \sim 0.0566 \mathrm{mg} \cdot \mathrm{m}^{-2} \cdot \mathrm{h}^{-1}$ 和 $0.0006 \sim 0.0149 \mathrm{mg} \cdot \mathrm{m}^{-2} \cdot \mathrm{h}^{-1}$ 。季节排放量分别为 0.32 (未施肥) 和 $0.54 \mathrm{~kg} \cdot \mathrm{hm}^{-2}$ (施肥) (图 $1 \mathrm{~b}$ )。

\subsubsection{3 稻田吸收 $\mathrm{CO}_{2}$}

实验中测定 $\mathrm{CO}_{2}$ 的通量是包括水稻光合固定、 水稻呼吸和土壤呼吸在内的一个综合通量, 该指标 能够全面的反映稻田生态系统对大气组分的调节功 能。研究中根据实验测定的 $\mathrm{CO}_{2}$ 气体浓度变化,计 算不同日期稻田 $\mathrm{CO}_{2}$ 排放通量 (因所有的测定值全 为负值, 所以将其取正, 并称之为 $\mathrm{CO}_{2}$ 吸收通量)。

实验研究结果显示, 稻田 $\mathrm{CO}_{2}$ 吸收通量在抽穗 扬花期较高, 然后逐渐减少, 至成熟期有所回升(图 1c)。水稻播种后 $70 \mathrm{~d}$ 是水稻生物量增加最快的抽 穗扬花期, 其 $\mathrm{CO}_{2}$ 吸收通量达最大值, 然后光合作用 强度减弱, 同时由于持续高温导致水稻植株呼吸和 土壤呼吸作用增强, 稻田 $\mathrm{CO}_{2}$ 吸收通量逐渐下降。 至成熟期, 虽然植株光合作用进一步减弱, 但稻田 (特别是未施肥处理) $\mathrm{CH}_{4}$ 的急速增加, 大量的 $\mathrm{CO}_{2}$ 被还原成 $\mathrm{CH}_{4}, \mathrm{CO}_{2}$ 排放量减少, 所以稻田 $\mathrm{CO}_{2}$ 吸收
通量有所回升。施肥和未施肥稻田 $\mathrm{CO}_{2}$ 吸收通量变 化范围为 $347.63 \sim 730.20 \mathrm{mg} \cdot \mathrm{m}^{-2} \cdot \mathrm{h}^{-1}$ 和 $205.06 \sim$ $679.51 \mathrm{mg} \cdot \mathrm{m}^{-2} \cdot \mathrm{h}^{-1}$ 。施肥和未施肥稻田 $\mathrm{CO}_{2}$ 的生 长季节吸收量分别为 19020 和 $15927 \mathrm{~kg} \bullet \mathrm{hm}^{-2}$ 。

\subsubsection{4 稻田温室气体调节}

本研究通过不同温室气体的 GWP 值计算得到 的稻田生态系统对大气温室气体浓度的综合调节作 用, 正值表示吸收大气中温室气体, 负值表示排放温 室气体。研究结果显示, 在整个生育期内稻田生态 系统对大气温室气体综合调节功能总体趋势是在抽 穗扬花期最大, 然后逐渐下降, 至成熟期略有回升 (图 1d)。施肥对稻田生态系统调节大气温室气体 有着明显影响。施肥的稻田生态系统抑制 $\mathrm{CH}_{4}$ 排 放, 同时少量的 $\mathrm{N}_{2} \mathrm{O}$ 排放对温室气体调节只产生轻 微影响, 因此稻田对大气 $\mathrm{CO}_{2}$ 调节的变化趋势决定 着对温室气体综合调节的变化趋势。未施肥稻田在 抽穗扬花期对温室气体调节起着积极作用, 其后由 于 $\mathrm{CH}_{4}$ 的大量排放和 $\mathrm{CO}_{2}$ 吸收通量的降低, 稻田对 大气温室气体调节起着消极作用, 并在播种后 $99 \mathrm{~d}$ 达到最低(图 1d)。施肥和未施肥的稻田温室气体 调节日变化范围分别为 $-1.42 \sim 39.71 \mathrm{~kg} \cdot \mathrm{hm}^{-2}$ ・ $\mathrm{d}^{-1}\left(\mathrm{CO}_{2}\right.$-C 当量 $)$ 和 $-50.56 \sim 25.60 \mathrm{~kg} \cdot \mathrm{hm}^{-2} \cdot \mathrm{d}^{-1}$ ( $\mathrm{CO}_{2}-\mathrm{C}$ 当量)。施肥和未施肥的稻田温室气体季节 调节物理量分别为 3774 和 $1135 \mathrm{~kg} \cdot \mathrm{hm}^{-2}$ (均为 $\mathrm{CO}_{2}$-C 当量)。而 Robertson 等(2000)的研究结果表 明, 一年生作物系统对大气温室气体没有净吸收作 用。该结果与本研究存在差异的主要原因是 Robertson 等(2000) 考虑了作物系统中人为投入 (化 肥、石灰、燃料)生产过程中排放的温室气体, 同时认 为作物收获也导致农田碳素的损失 ( $\mathrm{CO}_{2}$ 排放); 而 在本研究中, 没有计算人为投入温室气体排放, 并且 将作物固定的碳也计作农田生态系统吸收大气中 
$\mathrm{CO}_{2}$ 。

2.3.2 稻田生态系统温室气体调节价值量

研究结果显示, 在水稻生长发育期间, 未施肥稻 田 $\mathrm{CO}_{2}$ 吸收和 $\mathrm{N}_{2} \mathrm{O}$ 排放日价值保持相对稳定, 而 $\mathrm{CH}_{4}$ 排放和温室气体调节日价值变化幅度较大, 且 温室气体调节日价值变化趋势很大程度上受 $\mathrm{CH}_{4}$ 排放日价值变化趋势影响 (图 2)。各气体调节日价 值变化范围分别为 $10.11 \sim 33.51 \mathrm{yuan} \cdot \mathrm{hm}^{-2} \cdot \mathrm{d}^{-1}$ $\left(\mathrm{CO}_{2}\right) 、-0.24 \sim-0.01$ yuan $\cdot \mathrm{hm}^{-2} \cdot \mathrm{d}^{-1}\left(\mathrm{~N}_{2} \mathrm{O}\right)$ 、 $-61.22 \sim-4.04$ yuan $\bullet \mathrm{hm}^{-2} \cdot \mathrm{d}^{-1}\left(\mathrm{CH}_{4}\right)$ 和 -38.07 $\sim 19.28$ yuan $\bullet \mathrm{hm}^{-2} \cdot \mathrm{d}^{-1}(\mathrm{GHGs})$ 。

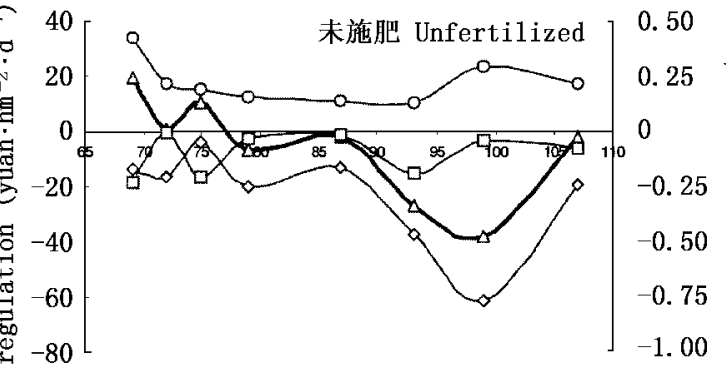

密

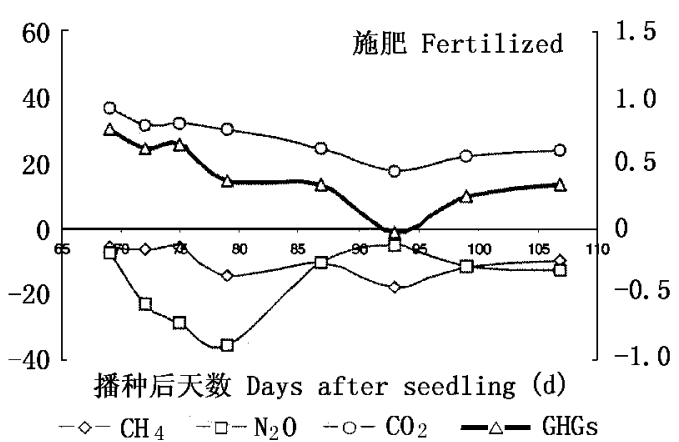

图 2 稻田生态系统温室气体调节价值量

Fig. 2 The seasonal fluctuation of values by GHGs regulation from paddy fields

施肥稻田气体调节日价值在水稻生育期内呈现 不同的变化趋势: $\mathrm{CO}_{2}$ 吸收、 $\mathrm{CH}_{4}$ 排放和温室气体调 节日价值变化幅度相对较小, 而 $\mathrm{N}_{2} \mathrm{O}$ 排放日价值出 现较大波动, 特别是播种后 $75 \mathrm{~d}$ 施加尿素导致 $\mathrm{N}_{2} \mathrm{O}$ 排放的负价值在播种后 $79 \mathrm{~d}$ 出现极小值 (图 2)。由 于稻田 $\mathrm{N}_{2} \mathrm{O}$ 排放日价值的绝对值相对较小, 其在生 育期内的大幅波动对温室气体调节综合日价值的影 响非常微弱; 而 $\mathrm{CO}_{2}$ 吸收和 $\mathrm{CH}_{4}$ 排放的价值决定了 温室气体调节日价值的变化趋势。在水稻生育期 内, 各气体调节日价值变化范围分别为 $17.14 \sim$ 36.01 yuan $\bullet \mathrm{hm}^{-2} \cdot \mathrm{d}^{-1}\left(\mathrm{CO}_{2}\right) 、-0.89 \sim-0.14$ yuan $\mathrm{hm}^{-2} \cdot \mathrm{d}^{-1}\left(\mathrm{~N}_{2} \mathrm{O}\right) 、-18.08 \sim-5.87$ yuan $\cdot \mathrm{hm}^{-2} \cdot \mathrm{d}^{-1}$ $\left(\mathrm{CH}_{4}\right)$ 和 $-1.07 \sim 29.90$ yuan $\bullet \mathrm{hm}^{-2} \cdot \mathrm{d}^{-1}(\mathrm{GHGs})$ 。
施肥与否对稻田各温室气体调节日价值有着不 同的影响: 对稻田 $\mathrm{CO}_{2}$ 吸收日价值而言, 施肥并不比 未施肥稻田有显著优势; 施肥能明显加剧稻田 $\mathrm{N}_{2} \mathrm{O}$ 的排放, 增强了稻田 $\mathrm{N}_{2} \mathrm{O}$ 排放产生负效应; 施肥能 有效抑制 $\mathrm{CH}_{4}$ 排放, 缓解了稻田 $\mathrm{CH}_{4}$ 排放产生的负 价值; 施加适量肥料可促进稻田对大气温室气体的 吸收, 发挥稻田对温室气体的积极调节作用。

\section{3 结 论}

施肥稻田生物生产量在整个生长季内都大于未 施肥稻田, 施氮肥的稻田 $\mathrm{O}_{2}$ 日释放量极值为未施肥 稻田极值的 1.5 倍。施肥和未施肥稻田 $\mathrm{O}_{2}$ 释放的 日价值量最大值分别为 190.72 和 289.93 yuan $\cdot \mathrm{hm}^{-2} \cdot \mathrm{d}^{-1}$ 。

在整个生育期内, 施肥和未施肥稻田 $\mathrm{CH}_{4}$ 排放 通量波动范围分别为 $4.86 \sim 14.96 \mathrm{mg} \cdot \mathrm{m}^{-2} \cdot \mathrm{h}^{-1}$ 和 $3.34 \sim 50.67 \mathrm{mg} \cdot \mathrm{m}^{-2} \cdot \mathrm{h}^{-1} ; \mathrm{N}_{2} \mathrm{O}$ 排放通量范围分别 为: $0.0086 \sim 0.0566 \mathrm{mg} \cdot \mathrm{m}^{-2} \cdot \mathrm{h}^{-1}$ 和 $0.0006 \sim$ $0.0149 \mathrm{mg} \cdot \mathrm{m}^{-2} \cdot \mathrm{h}^{-1} ; \mathrm{CO}_{2}$ 吸收通量变化范围为 $347.63 \sim 730.20 \mathrm{mg} \cdot \mathrm{m}^{-2} \cdot \mathrm{h}^{-1}$ 和 $205.06 \sim 679.51 \mathrm{mg} \bullet$ $\mathrm{m}^{-2} \cdot \mathrm{h}^{-1}$ 。以 $\mathrm{CO}_{2}$ 当量纯 $\mathrm{C}$ 计算的施肥和未施肥的 稻田温室气体调节通量变化范围分别为 $-1.42 \sim$ $39.71 \mathrm{~kg} \cdot \mathrm{hm}^{-2} \cdot \mathrm{d}^{-1}$ 和 $-50.56 \sim 25.60 \mathrm{~kg} \cdot \mathrm{hm}^{-2}$ ・ $\mathrm{d}^{-1}$ 。

施肥与未施肥稻田 $\mathrm{CO}_{2}$ 吸收日价值无显著差 异; 施肥能明显增加稻田 $\mathrm{N}_{2} \mathrm{O}$ 排放产生的负效应, 并能有效抑制 $\mathrm{CH}_{4}$ 排放, 缓解了稻田 $\mathrm{CH}_{4}$ 排放产生 的负价值。

\section{参 考 文 献}

Adhya TK, Rath AK, Gupta PK, Rao VR, Das SN, Parida KM, Parashar DC, Sethunathan N (1994). Methane emission from flooded rice fields under irrigated conditions. Biology and Fertility of Soils, 18, 245-248.

Björklund J, Karin EL, Torbjörn R (1999). Impact of production intensity on the ability of the agricultural landscape to generate ecosystem services: an example from Sweden. Ecological Economics, 29, $269-291$.

Cao JL (曹金留), Xu H (徐华), Zhang HK (张宏康), Xing GX (邢光喜), Ren LT (任立涛), Yang BL (杨保林) (1999). Characteristics of $\mathrm{N}_{2} \mathrm{O}$ emission from rice fields in the hilly area of southern Jiangsu Province. Chinese Journal of Ecology (生态学杂志), 18(3), 6-9. (in Chinese with English abstract)

Costanza R, d'Arge R, de Groot R, Farber S, Grasso M, Hannon B, Limburg K, Naeem S, Paruelo J, O' Neill RV, Paruelo J, 
Raskin RG, Sutton P, van den Belt M (1997). The value of the world's ecosystem services and natural capital. Nature, 387, $253-260$.

Daily GC (1997). Nature's Service: Societal Dependence on Natural Ecosystems. Island Press, Washington DC.

China Environment Protection Administration (国家环境保护局) (1997). The National Report of Biodiversity in China (中国生 物多样性国家报告). China Environmental Science Press, Beijing. (in Chinese)

IPCC (1992). Climate Change 1992: the Supplementary Report to the IPCC Scientific Assessment. Cambridge University Press, Cambridge.

Jiang JY (蒋静艳), Huang Y (黄耀) (2001). Advance in research of $\mathrm{N}_{2} \mathrm{O}$ emission from agricultural soils. Agro-Environmental Protection (农业环境保护), 20, 51 - 54. (in Chinese with English abstract)

Lindau CW, Bollich BK, Delaune RD, Patrick WH, Law VJ (1991). Effect of the urea fertilizer and environment factors on $\mathrm{CH}_{4}$ emissions from a Louisiana rice field. Plant and Soil, 136, $195-203$.

Mah RA, Smith MR (1981). The methanogenic bacteria. In: Starr MP, Stolp H, TruÈper HG, Balows A, Schlegel HG eds. The Prokaryotes. Springer, Berlin, 948 - 977.

Nouchi I, Hosono T, Aoki K, Minami K (1994). Seasonal variation in methane flux from rice paddies associated with methane concentration in soil water, rice biomass and temperature, and its modeling. Plant and Soil, 161, $195-208$.

Ouyang ZY (欧阳志云)，Wang XK (王效科)，Miao H (苗鸿) (1999) . A primary study on Chinese terrestrial ecosystem services and their ecological-economic values. Acta Ecologica Sinica (生态学报), 19, 607 - 613. (in Chinese with English abstract)

Paoletti M, Pimentel D, Stinner B, Stinner D (1992). Agroecosytem biodiversity: matching production and conservation biology. Agriculture, Ecosystems and Environment, 40, 3-23.

Robertson GP, Paul EA, Harwood RR (2000). Greenhouse gases in intensive agriculture: contributions of individual gases to the radiative forcing of the atmosphere. Science, 289, $1922-1925$.
Shangguan XJ (上官行健), Wang MX (王明星) (1993). Measures to control $\mathrm{CH}_{4}$ emission from paddy fields. Advance in Earth Sciences (地球科学进展), 8(5), 55-62. (in Chinese with English abstract)

Singh S, Singh JS, Kashyap AK (1999) . Methane flux from irrigated rice fields in relation to crop growth and N-fertilization. Soil Biology and Biochemistry, 31, 1219 - 1228.

Wang XL (王修兰) (1996). The estimation on crop absorbing $\mathrm{CO}_{2}$ under current and double $\mathrm{CO}_{2}$ condition in the world. Acta Meteorologica Sinica (气象学报), 54, 466-473. (in Chinese with English abstract)

Wang ZP, DeLaune RD, Masscheleyn PH, Patrick JWH (1993). Soil redox and $\mathrm{pH}$ effects on methane production in a flooded rice soil. Soil Science Society of America Journal, 57, 382 - 385.

Whalenm SC, Reebergh WS, Kizer KS (1991). Methane consumption and emission by taiga. Global Biochemical Cycles, 5, 261 273.

Xie GD (谢高地), Lu CX (鲁春霞), Leng YF (冷允法), Zheng D (郑度), Li SC (李双成) (2003). Ecological assets valuation of the Tibetan Plateau. Journal of Natural Resources (自然资源学报)，18，189-196. (in Chinese with English abstract)

Yang SS, Chang HL (1998) . Effect of environmental conditions on methane production and emission from paddy soil. Agriculture, Ecosystems and Environment, 69, 69-80.

Yang SS, Chang HL (1999). Diurnal variation of methane emission from paddy fields at different growth stages of rice cultivation in Taiwan. Agriculture, Ecosystems and Environment, 76, 75-84. Zhou WJ (周卫军), Kai R (凯荣), Zhang GY (张光远) (2003) . Some effects of inorganic fertilizer and recycled crop nutrients on soil nitrogen supply and paddy rice production in the red earth region of China. Acta Ecologica Sinica (生态学报), 23, 914 - 921. (in Chinese with English abstract)

Zou JW (邹建文), Huang Y (黄耀), Zong LG (宗良纲), Zheng XH (郑循华), Wang YS (王跃思) (2003). A field study on $\mathrm{CO}_{2}, \mathrm{CH}_{4}$ and $\mathrm{N}_{2} \mathrm{O}$ emissions from rice paddy and impact factors. Acta Scientiae Circumstantiae (环境科学学报), 23, 758 - 764. (in Chinese with English abstract)

责任编委: 李凤民 责任编辑: 刘丽娟 